\title{
Apropriando-se de Johannes Vermeer: revisitando o século XVII
}

Resumo

Este artigo pretende discutir alguns procedimentos envolvidos no conceito de apropriação, relacionando-o com os vários diálogos que emergiram na cultura visual atual ao redor do pintor holandês Johannes Vermeer. A ideia de apropriação parte do princípio de que a cultura e, especificamente, as imagens produzidas ao longo dos séculos nas artes plásticas nos pertencem e constroem constantemente nossa imaginação. Ao invés de negar o passado para afirmar uma suposta originalidade, $\mathrm{o}$ artista contemporâneo não receia em recriar a partir de obras já existentes, criando assim um diálogo entre o passado e o presente. Iremos refletir qual o significado atribuído a este artista atualmente.

Palavras-chave:

Apropriação; Arte Contemporânea; Johannes Vermeer 


\section{Appropriating Johannes Vermeer: Revisiting the 17th century}

\section{CRISTINA SUSIGAM}
Abstract
This article intends to discuss some procedures involved in the concept of appropriation, relating it to the various dialogues that emerged in the current visual culture around the Dutch painter Johannes Vermeer. The idea of appropriation assumes that the culture and specifically the images produced over the centuries in the visual arts belong to us and constantly build our imagination. Rather than denying the past to assert an alleged originality, the contemporary artist is not afraid to recreate from existing works, creating a dialogue between the past and the present. We will reflect on the significance attributed to this artist today. 


\section{Apropiándose de Johannes Vermeer: revisitando el siglo XVII}

\section{Resumen}

Este artículo pretende discutir algunos procedimientos implicados en el concepto de apropiación, relacionándolo a los diversos diálogos que surgieron en la cultura visual actual en torno al pintor holandés Johannes Vermeer. La idea de apropiación supone que la cultura (específicamente, las imágenes producidas a lo largo de los siglos en las artes plásticas), nos pertenece y constantemente construye con nuestra imaginación. En lugar de negar el pasado para reivindicar una presunta originalidad, el artista contemporáneo no teme recrear partiendo de obras existentes, estableciendo un diálogo entre el pasado y el presente. Vamos a reflexionar sobre el significado atribuido a este artista en la actualidad.

Palabras clave:

Apropiación; Arte contemporáneo; Johannes Vermeer. 
A história da arte é uma disciplina sempre em movimento. Seus estudos não podem ficar agregados a velhas correntes. Ao estudar a História da Arte temos que fazer uma inter-relação entre passado e presente, mas além disso, pensar que que existe uma relação dos artistas que produziram as imagens e aqueles que as apreciam. Não podemos desassociar os acontecimentos da vida em sociedade da produção artística de sua época. Fatos e representação artística estão vinculados. E segundo Fernando Hernández: "A cultura visual pode ser considerada uma das maneiras mais dinâmicas para repensar a História da Arte" (HERNANDÉZ, 2005, p. 13-14). Portanto, a cultura visual abre uma nova reflexão para mudar métodos e olhares sobre a História da Arte.

Logo, não podemos estranhar que Michael Baxandall (1933-2008), em Padrões de Intenções (2006), já apontasse para um novo direcionamento teórico. Como Peter Burke (1937-), em Testemunha Ocular - O uso das imagens como evidência histórica (2017), Baxandall evidencia a importância da leitura das imagens como fontes históricas, salientando que as imagens, além dos documentos oficiais, são testemunhos visuais que nos ajudam a compreender significados ocultos de contextos específicos.

Os estudos de obras de artes, em especial das telas de um determinado período histórico, constituem um amplo universo de informações a ser explorado. Aproximando-se do nosso objeto de estudo, o artista Johannes Vermeer (1632 - 1675) e a reverberação de suas obras ao longo da História da Arte, a historiadora de arte Svetlana Alpers (1936-), em sua obra A Arte de Descrever (1998), afirma que na Holanda a "cultura visual" era comum no âmbito social: "o olho era o instrumento fundamental da autorepresentação, e a experiência visual um modo 
fundamental de autoconsciência" (ALPERS, 1998, p. 39). As imagens estão projetadas nas residências. Retratando o cotidiano, a pintura holandesa documenta ou mesmo representa o comportamento dessa sociedade, diferentemente da dos italianos, que enaltece os feitos heroicos e históricos, considerados eventos únicos.

Outras teorias surgiram no sentido de dar maior evidência ao estudo das imagens que contribuem para o estudo da cultura visual. Na introdução à edição brasileira do livro de Baxandall, Heliana Angotti Salgueiro faz referência ao livro Diante do Tempo (2016), de Georges Didi-Huberman (1953-), quando este levanta questões pertinentes em relação à sobrevivência das imagens ao longo do tempo, conceitos que vão nos ajudar e dar suporte ao nosso estudo à guisa de método:

[...] a questão da transformação, a da reinvenção de um instrumento mental, a do leque de possibilidades, a da montagem das diferenças que caracterizam uma simples imagem, entre elas a montagem de quadros mentais de vários tempos ou a dinâmica da memória, que está presente no artista, e que se revela fora do seu próprio tempo. (SALGUEIRO, 2005, p. 16, grifo da autora).

Nosso estudo pretende focar-se na sobrevivência das imagens de Johannes Vermeer, através do termo empregado pela história e pela crítica da Arte, a apropriação, e através de alguns artistas da contemporaneidade. Na mesma introdução acima referida, Salgueiro (2006), seguindo sugestão de Baxandall, faz uma relação de palavras que irá tratar do objeto de estudo desta pesquisa, como: "apropriar-se de", referir-se a", "retomar", "citar", "assimilar", “integrar", prolongar", 'calcar-se sobre”, "transformar”, todas no sentido de extrair um fragmento de um contexto vivo e inseri-lo numa nova relação com o passado, ao qual estava vinculado, atribuindo-lhe uma nova função a partir desse novo.

Neste processo, encontramos artistas que articulam sua proposta com uma nova perspectiva. Esses artistas vinculam sua estética e releitura de imagens icônicas, segundo o termo cunhado por Aby Warbrug (1866 - 1929): nachleben, ou seja, sobrevivência das imagens, nas palavras de Georges Didi-Huberman (1953 -) (2013), ou pós-vida das imagens, na concepção de Giorgio Agamben (1942 -) (2010), em que as imagens estão sempre em um processo de reinterpretação, inseridas em um novo contexto. As nachleben são, assim, um estudo intensivo daquilo que permanece e sobrevive desta 
relação temporal e não do que já passou, sendo que esta vida póstuma, dotada de movimento, se estabelece numa ideia de fluxo, de ondas mnésicas do tempo que nos levam até o surgimento de uma hipótese - a iconologia dos intervalos assente numa lei de boa vizinhança - sem a qual não seria possível reconhecer a vida em movimento inscrita na história dos fantasmas para adultos (DIDI-HUBERMAN, 2013).

Se partirmos da premissa de que as pinturas de Vermeer são consideradas imagens de culto, e estão estabelecidas dentro do cânone da História da Arte, permanecendo vivas, são imagens "sobreviventes", nosso questionamento dirige-se a estas novas imagens criadas a partir do referencial imagético do mestre holandês. Serão estas imagens também "sobreviventes"? Ou apenas cumprem uma função de ressignificação, ao destruir a autoridade tradicional, que não será perdurável no tempo?

\section{Johannes Vermeer: introdução a sua vida e obra}

Johannes Vermeer, um artista holandês do século XVII cujo trabalho consiste na existência de apenas trinta e cinco pinturas e cuja vida permanece, na sua maior parte, um mistério para nós, é um artista que se tem tornado cada vez mais conhecido e admirado em nossa cultura e arte contemporânea. Não existe dúvida de que, estimulado pelo senso de mistério e intriga que rodeia o artista e sua obra, o público transformou Vermeer, que era um artista esquecido, em um artista extremamente venerado. Porém, se estes aspetos da história direcionam o olhar para o pintor, são as suas pinturas que continuam a manter o nosso interesse e fixo olhar.

No contexto dos estudos efetuados pelos maiores estudiosos de Vermeer na contemporaneidade, Arthur K. Whelock, Jr. e Walter Liedtke, o último recentemente falecido, é bastante relevante e de certa forma necessário compreender e conhecer a cronologia de vida de um artista de que poucos detalhes se conhecem, como é caso de Johannes Vermeer. Muito embora nunca tenha sido realmente esquecido ou subestimado, Johannes Vermeer é um nome relativamente recente visto que o seu "redescobrimento" data de meados do século XIX. Nessa época, o seu reconhecimento aumenta consideravelmente, ao mesmo tempo em que se criam as premissas de um destaque científico da sua obra e se publicam escritos relacionados com ela.

Ainda que um escasso número de informações a respeito de Vermeer tenha chegado até os nossos dias, nos últimos 
anos, os historiadores têm conseguido reunir uma série de dados sobre a sua vida e sua carreira artística, utilizando para isso os arquivos de documentos existentes em conjunto com o conhecimento da vida social e artística da Holanda do século XVII, como também a análise dos trinta e cinco quadros deixados por Vermeer. Os créditos devem-se, primeiramente, a P.T.A. Swillens por ter, em 1952, traçado as primeiras linhas sobre a vida de Vermeer em Johannes Vermeer. Painter of Delft: 1632-1675. No entanto, o grande progresso foi feito nos anos de 1980, graças ao estudo minucioso do economista John Michael Montias (1998), no seu livro, Vermeer and His Millieu: A Web Social History, que pacientemente organizou de uma forma coerente os testemunhos legais, testamentos, escrituras, penhoras, inventários, notas promissórias e outros documentos oficiais. Estes documentos remontam a duas gerações anteriores à do avô materno de Vermeer e continuam durante todo o século XVII, mesmo após a morte do pintor. A pesquisa rigorosa e detalhada de Montias (1998) reproduz um retrato da sociedade em que Vermeer vivia e contribuiu para um profundo conhecimento do homem e da sua arte.

Vermeer nasceu em Delft em 1632, e presume-se que era protestante. Da sua infância sabe-se apenas que seus genitores, Reynier Vos e Dymphna Balthasardr, mantinham uma taberna na Praça do Mercado, atividade que seu pai mais tarde abandona para dedicar-se ao comércio de obras de arte e à produção de sedas preciosas, inscrevendo-se também na corporação de Deft como pintor. Quando o pequeno Jan conta quinze anos, Reyner Vos adota oficialmente o nome de Van der Meer ou Vermeer, pelo qual será conhecido doravante. Só muitos anos mais tarde tem-se uma indicação sobre a vida do pintor: é em 1653, quando se casa com Catharina Bolnes, sugerindo sua conversão ao catolicismo. No mesmo ano, ele se regista como mestre da pintura na Confraria de São Lucas em Delft, onde foi eleito presidente da Confraria entre os anos de 1662-63 e 1671-72. (WHEELOCK JUNIOR, 1995, p. 17).

Até meados do século XIX, o nome de Vermeer permanece, se não esquecido, apenas citado vagamente, pois ainda não haviam reconhecido em Vermeer, como hoje acontece, o maior dos "intimistas" que incansavelmente representou cenas da vida doméstica. Talvez, a explicação deste fato possa ser encontrada em grande parte na personalidade do próprio artista. Primeiro, sua escassa produção, depois, a sua fama não estava solidamente estabelecida na sua época para poder resistir ao tempo. Em 1866, Etienne Joseph 
Théophile Bürger-Thoré (1807-1869), um crítico francês, conhecido como Bürger-Thoré, concluiu o primeiro grande estudo sobre Vermeer. Esta monografia, dividida em três partes, é o primeiro grande estudo consagrado a Vermeer. Publicada em forma de artigos na Gazette des Beaux-Arts, o estudo classifica Vermeer como "grande mestre", com lugar reconhecido na história da arte e uma reputação perante o grande público. Foi um primeiro passo para a elevação de Vermeer à altura dos grandes mestres holandeses da Idade de Ouro. Apesar de impreciso e nem sempre exato, foi um trabalho árduo. Vermeer assinou, quando muito, a metade de suas criações, e, no século XIX, muitas delas foram atribuídas a outros pintores - mais famosos e mais valiosos.

\section{Megaexposição Johannes Vermeer (National Gallery Washington/Haia, 1995-1996)}

A exposição Johanner Vermeer da National Gallery of Art é considerada por muitos estudiosos o mais importante evento dos tempos contemporâneos sobre Vermeer, proporcionando uma oportunidade única de aceder às pinturas originais, analisar a força com que as reproduções das obras do pintor proliferam dentro da cultura americana e a maneira como uma exposição pode instruir o contemporâneo entendimento do significado da arte. A exposição que esteve patente durante apenas três meses demorou mais de oito anos a ser montada e tornou-se um dos eventos de reconhecimento internacional e amplamente aclamado como a exposição de uma vida. Por trás desta exposição, estava mais uma vez o empenho de Arthur Wheelock, curador responsável pela pintura barroca do Norte da Europa na National Galley of Art e professor de história da arte da University of Maryland.

Embora pequena em escala, incluindo apenas vinte e uma pinturas, a exposição continha mais da metade das obras conhecidas de Vermeer. O estilo inconfundível da obra do mestre holandês - refinamento, perfeição e inerente beleza - é cuidadosamente demonstrado e discutido nas pesquisas levadas a cabo por Wheelock durante anos, agora com a tangível evidência de um significativo número de verdadeiros originais de Vermeer.

As mídias e o público em geral entenderam e envolveram-se com estes temas e a exposição tornou-se em uma exposição aclamada como um ato de brilhantismo, inspiração e diplomacia. Os estudiosos e o público leigo acorreram em 
multidões a Washington para ver as muitas obras do artista que tinham estado reunidas juntas nos últimos trezentos anos. Desde o leilão para a venda das obras de Vermeer em 1696, vinte anos após a morte do artista, era a primeira vez que tantas obras de Vermeer estavam reunidas em um único espaço. A proximidade das pinturas de Vermeer, interagindo umas com as outras, proporcionou ao observador a vantagem adicional de ver as obras como elas tinham estado no século XVII - isso e também o fato de se suspeitar que vinte das vinte e uma pinturas incluídas na exposição Johannes Vermeer tinham sido propriedades de um único patrono: Pieter Claesz van Ruijven.
Figura 1 - Imagens de capas de romances inspiradas nas obras de Johannes Vermeer (esquerda para direita, de cima para baixo: O quadro da menina de azul; A Filha de Vermeer; A dança geométrica; Moça com brinco de pérola e A Lição de Música). Fonte: Autoria própria, 2017.

\section{A sobrevivência das imagens na contemporaneidade}

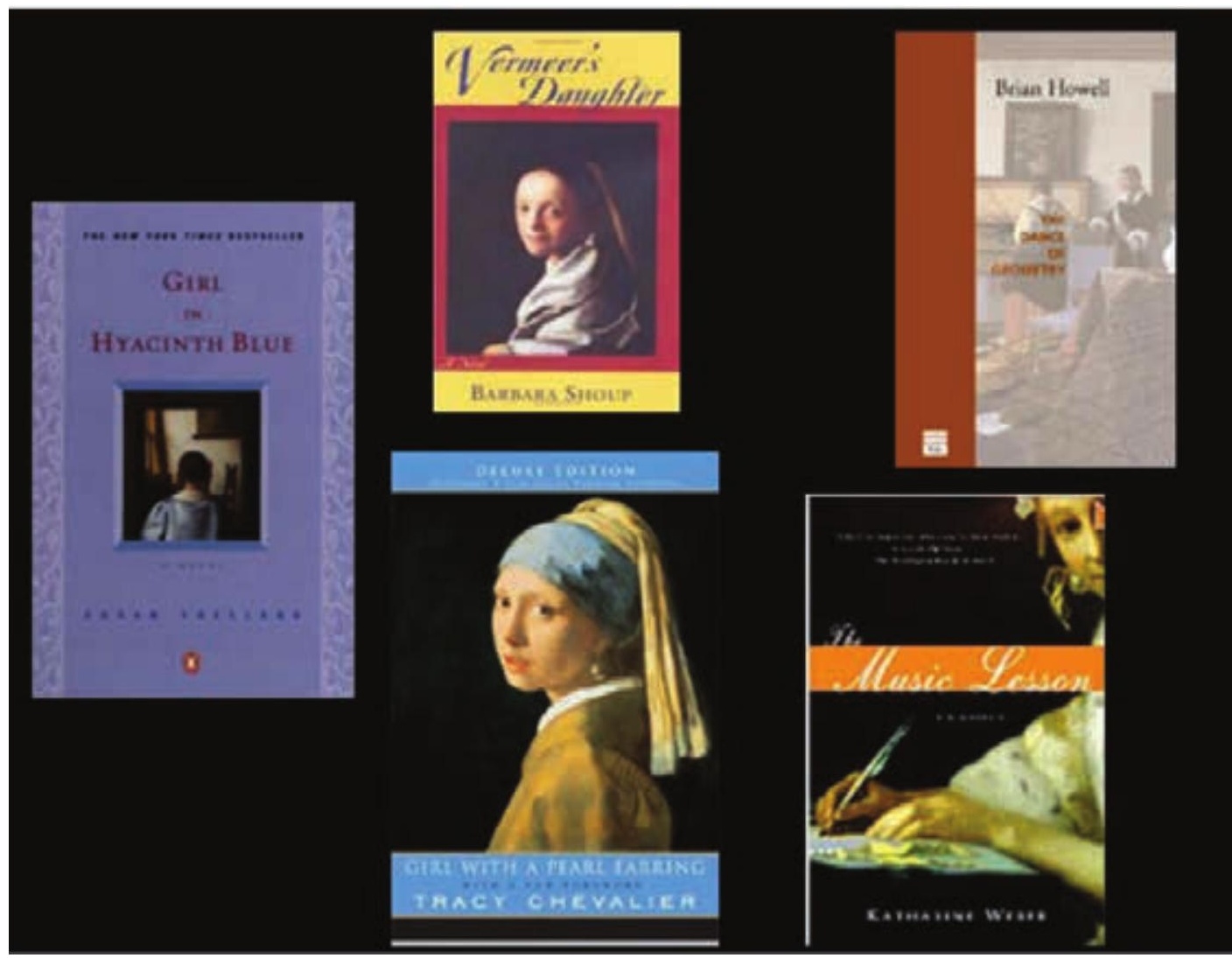


A partir desta exposição, que deu relevo e trouxe o mestre holandês para o centro da discussão na contemporaneidade, dando visibilidade e amplo acesso às suas obras e trazendo uma série de "apropriações", optou-se por fazer um levantamento iconográfico expressivo para a investigação empreendida. Num primeiro momento um amplo número de imagens foi selecionado dentro de um rol muito diversificado de referenciais: imagens provenientes de capas de romances contemporâneos que se inspiraram na pintura de Johannes Vermeer para apropriarem-se da vida e obra do pintor (A Lição de Música [1998], de Katharine Weber [200o], Moça com Brinco de Pérola [1999], de Tracy Chevalier [2004], O quadro da menina de azul [1999], de Susan Vreeland [2002], A dança geométrica [2002], de Brian Howell [2002], A Filha de Vermeer [2003], de Barbara Shoup [2003]).

Frames de filmes - como no caso de Blade Runner (1982), em que a imagem de uma fotografia encontrada no quarto do hotel de um dos personagens (Leon), que será mais tarde usada por outro personagem (Deckard) na sua busca para localizar os replicants (androides) ilegais - foram baseados numa pintura de Vermeer. A fotografia, que será corporificada em várias cenas importantes em Blade Runner (1982), possui uma notável semelhança com $A$ Lição de Música (1662) de Johannes Vermeer e elementos de estilo e composição de Jan Van Dyck. As janelas do lado esquerdo, a disposição de muitos dos elementos composicionais e o desenho, de uma forma global, remetem para esta pintura de Vermeer. O enquadramento do filme, já no final, em conjunção com um piano, a música e o tema narrativo, tudo isso acentua a semelhança com A Lição de Música de Vermeer.

O filme de Terence Davies, The House of Mirth (200o), apropria-se da estética visual da pintura de Vermeer, recriando, através da luz e sombra, e dos enquadramentos, uma "tela". Outro filme que se apropria das pinturas de Vermeer utilizando-as como tema e fio condutor da narrativa, como um elemento de misse-en-scene, é All Vermeers in New York (1989-1990) de Jon Jost; a história passa-se na contemporaneidade e seus personagens buscam, através da arte, por um desejo não correspondido.

O telefilme Brush with Fate (2003), de Brent Shield, é a adaptação do romance de Susan Vreeland, Girl in Hyacinth Blue. O quadro utilizado como fio condutor da narrativa fílmica e do romance não é um verdadeiro Vermeer, foi uma pintura feita pelo artista plástico Jonathan Janson, que se 
apropria dos elementos de composição e estilo de Vermeer para criar a sua obra. A história passa do presente para o passado através dos vários proprietários da pintura até chegar à criação da obra do fictício Vermeer.

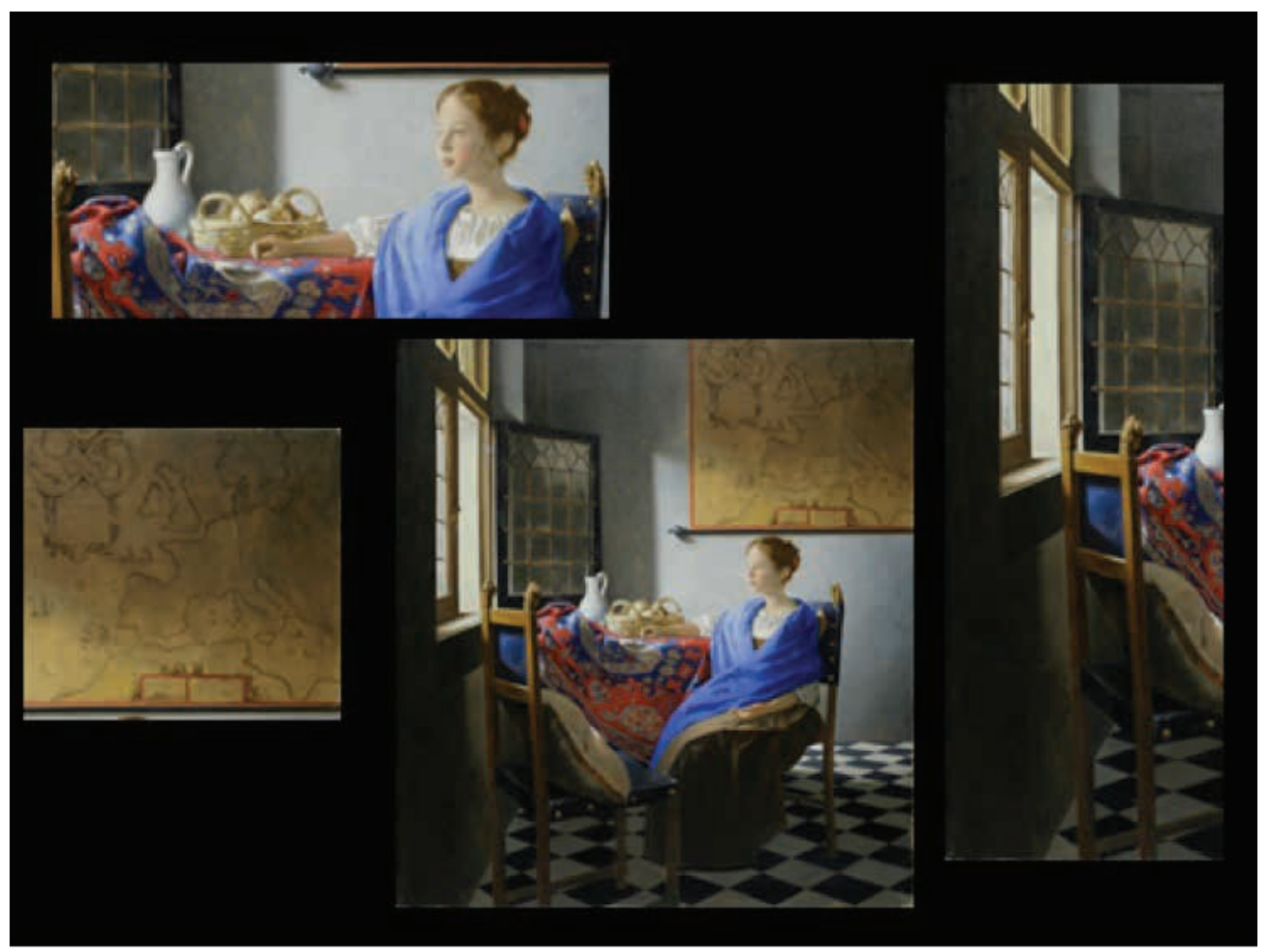

Entretanto, o mais famoso filme será Moça com brinco de Pérola (2003), de Peter Webber, baseado no romance homónimo de Tracy Chevalier. Aqui a apropriação é feita de forma fiel, ao recriar o ambiente do ateliê do artista, através da iluminação detalhista e cuidada de Eduardo Serra, diretor de fotografia. A história, além de se apropriar destes elementos composicionais, irá recriar os quadros do mestre holandês.

Vermeer também foi apropriado dentro do contexto da ópera contemporânea. Inspirado pela sua visita à exposição Johannes Vermeer no Mauritshuis em Haia, em 1996, o compositor Louis Andriessen criou Writing to Vermeer (1997-98), uma colaboração lírica com o realizador Peter Greenaway. A ópera, que incluía a característica mistura de imagem e texto de Greenaway, desenvolve-se ao redor de
Figura 2 - Girl in Hyacinth Blue (2002) de Jonathan Janson (1950-). Fonte: Óleo sobre tela: 45 x $40 \mathrm{~cm}$ - Hallmark art collection, St. Louis. 
uma viagem real que Johannes Vermeer empreendeu a Haia em 1672, e de uma série de cartas fictícias que ele recebeu de três mulheres - sua esposa, sua sogra e sua modelo, Saskia de Vries.

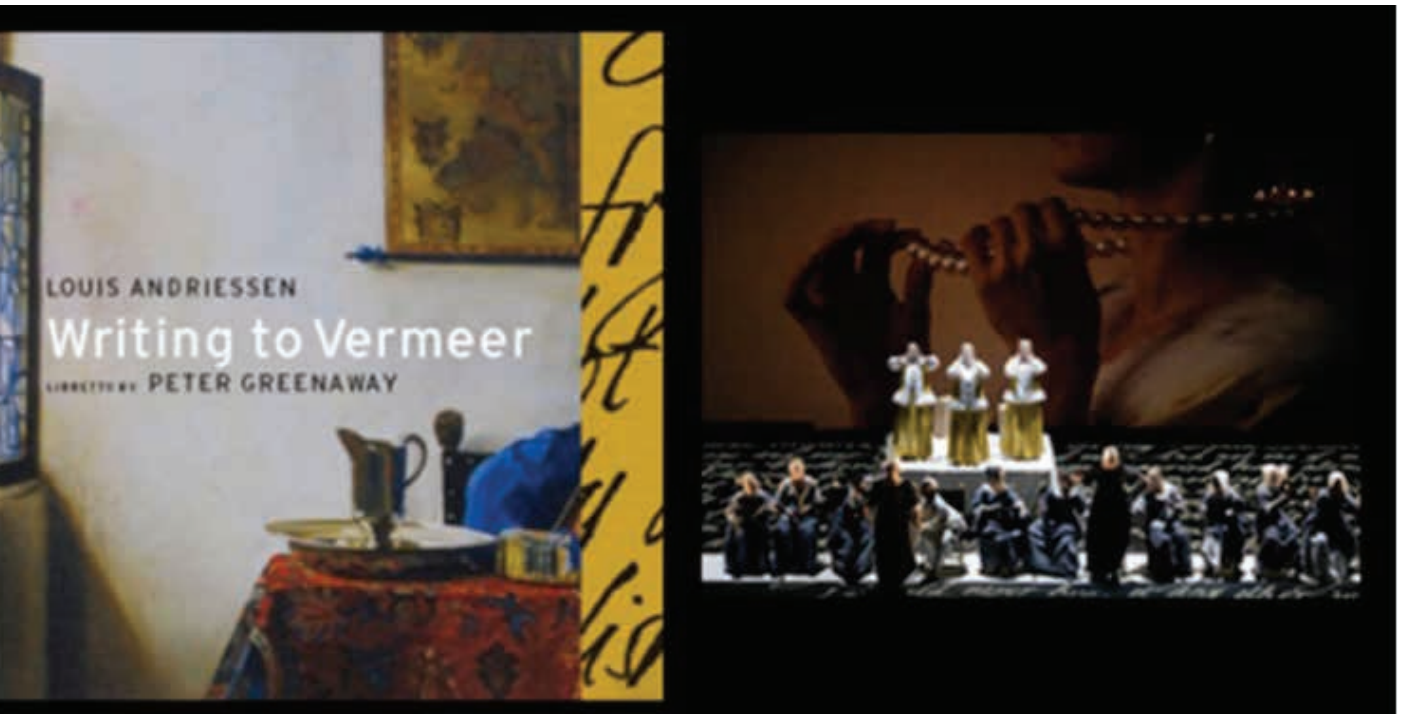

Figura 2: Capa do livreto $e$ cenário da ópera Escrevendo para Vermeer. Fonte: Autoria própria, 2017.
Muitas imagens foram apropriadas pelas artes plásticas, uma primeira seleção, ampla e aleatória, recaiu em diversos movimentos artísticos e numa variedade de artistas de diferentes quadrantes. Pintores, fotógrafos, escultores debruçaram-se sobre a obra de Vermeer e através de um novo olhar apropriaram-se e criaram suas obras. Apenas a título de conhecimento podemos citar o artista alemão Vilhelm Hammershoi (1864-1916) que se apropria através do tema e estilo; Salvador Dali (1904-1989) subverte as pinturas de Vermeer através do surrealismo; Gerhard Ritcher (1932-), pelo meio fotográfico, posiciona uma mulher, na contemporaneidade, que segura um documento, na mesma posição que as mulheres de Vermeer; Sophie Calle (1953-), através de um pano preto que simula a tela vazia onde deveria estar o quadro $A$ Lição de Música, fazendo assim o ocultamento da pintura de Vermeer, roubada em 1990, do Isabella Stewart Gardner Museum; Claes Oldenburg (1929-) apropria-se através de esculturas e pinturas dos instrumentos músicas retirados das pinturas de Vermeer. Outros artistas podem ser citados, como Bill Gekas, Tom Hunter (1965-) ou o irreverente Bansky (1974/75 -). 
Dentro deste mosaico foi necessário fazer uma escolha para efetuar o estudo da apropriação, através das "sobrevivências" das imagens de Vermeer na cultura contemporânea, recaindo sobre a obra de quatro mulheres que dialogam de maneiras diferentes com a obra do mestre holandês. Para este artigo, selecionamos a artista Jeannette Christensen, que nos parece ter relevância não apenas com a questão das sobrevivências das imagens, mas com a discussão da representação da mulher e nas reverberações com outras culturas.

\section{Jeannette Christensen}

Jeannette Christensen nasceu em 1958 na Noruega. Vive e trabalha em Oslo. Iniciou sua formação no Bergen National Academy of the Arts, em 1978-79, e posteriormente especializou-se em desenho gráfico entre 1979-82 e 1984-85, no Vestelandests Kunstakademi. Em 1982-83, participa de uma residência artística na École Nationale Supérieure des Beaux Arts, em Paris, e em 1992-93 participa do PS1 International Studio Program, em Nova Iorque. Foi professora convidada na Royal Danish Academy of Fine Arts, entre 1998-200, e professora adjunta, entre 2000-2007, na Bergen National Academy of the Arts.
Figura 4: Exposição da série The Passing of Time, 1994, de Jeannete Christensen, Polaroid. Fonte: Jeannette Christensen, 1994. Disponível em: <http:// www.jeannettechristensen.no/ the-passing-of-time-1994/>. Acesso em: 20 ago. 2018.

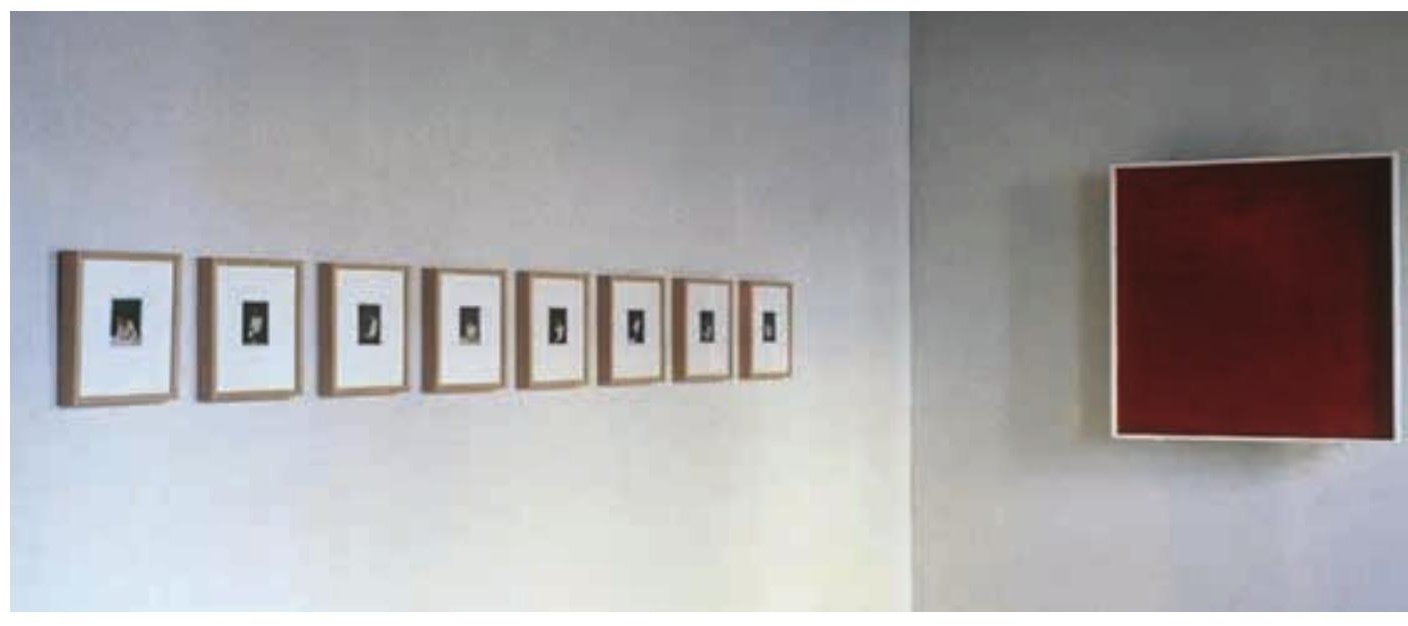

Quando Christensen conheceu Mieke Bal - a teórica que mais tem se debruçado e analisado a obra de Christensen, principalmente com o ensaio Jeannette Christensen's Time (BAL, 2009) publicado em 1997 e em Quoting Caravaggio: 
Contemporary Art, Preposterous History (BAL, 1999), de 1999 -, a artista havia feito uma série de polaroides intitulada The Passing of Time (1994) (Figura 4) e baseada na apropriação e reinterpretação de algumas pinturas de Vermeer. Christensen, fascinada pelas telas realistas de Vermeer em que mulheres executam acções diárias, utiliza em seu trabalho o meio fotográfico, neste caso, a fotografia em polaroide - uma máquina fotográfica que de alguma forma podemos aproximar da câmera escura. As fotografias produzidas pela artista norueguesa fazem uma releitura das mulheres do artista de Delft, ao executar as mesmas ações que as mulheres retratadas no século XVII. Ao remover as representações alegóricas das pinturas do mestre de Delft e com o auxílio da fotografia, Christensen procurou recriar uma espécie de qualidade instantânea que está presente nas pinturas do pintor holandês.

Christensen estava interessada em fazer sua própria interpretação, fora do contexto histórico - e iremos observar essa reinterpretação de forma mais clara quando a artista faz a apropriação das pinturas de Vermeer e coloca na composição homens nas tarefas domésticas, substituindo as mulheres, e, mais recentemente, foca num tema bem atual, uma mulher com a vestimenta própria de uma mulher muçulmana.

Figura 5: Holding Balance, 2014. Fonte: Jeannette Christensen, 2014. Disponível em: <http:// www.jeannettechristensen.no/ holding-balance/>. Acesso em: 20 ago. 2018.

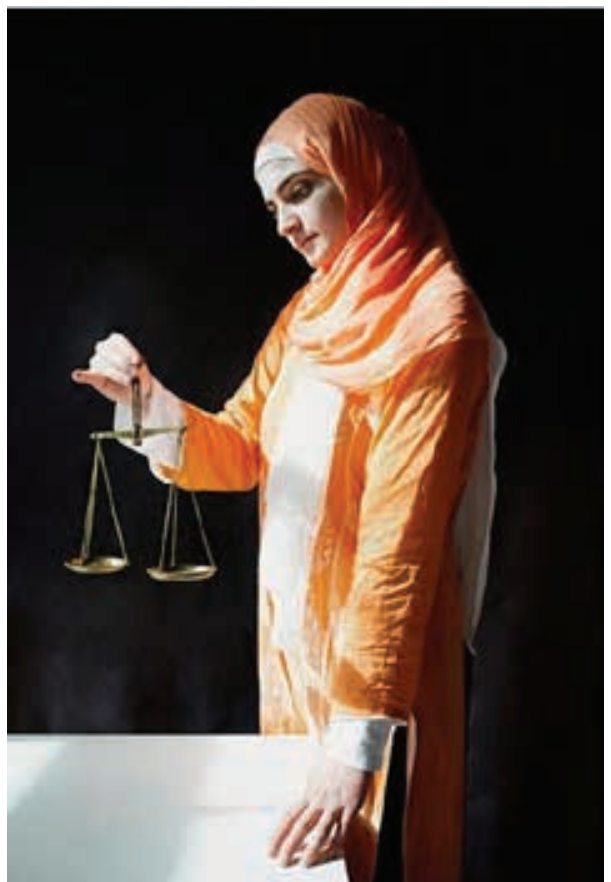


Numa série mais recente, como nos referimos, trocou as mulheres por homens; homens escrevendo ou lendo cartas de amor, vertendo leite ou bebendo de um copo (Figura 6). Essas polaroides foram justapostas com materiais gelatinosos que representam mais do que a substância, principalmente a transitoriedade e mudança.
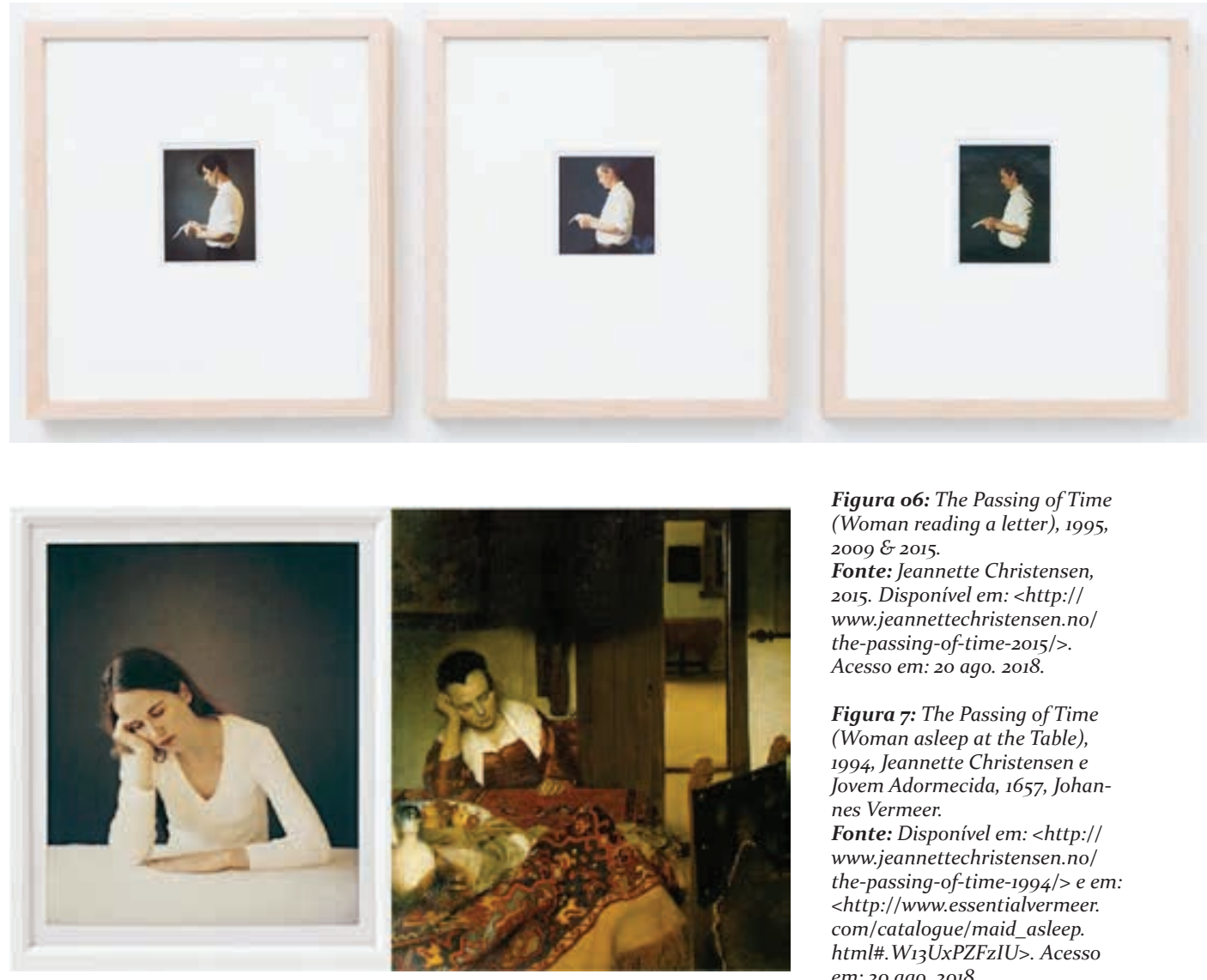

Figura o6: The Passing of Time (Woman reading a letter), 1995 , 2009 E 2015.

Fonte: Jeannette Christensen, 2015. Disponível em: $<$ http:// www.jeannettechristensen.no/ the-passing-of-time-2015/>. Acesso em: 20 ago. 2018.

Figura 7: The Passing of Time (Woman asleep at the Table), 1994, Jeannette Christensen e Jovem Adormecida, 1657, Johannes Vermeer.

Fonte: Disponível em: <http:// www.jeannettechristensen.no/ the-passing-of-time-1994/> e em: <http://www.essentialvermeer. com/catalogue/maid_asleep. html\#. W13UxPZFzIU>. Acesso em: 20 ago. 2018.

Citando, apropriando e combinando aspectos da história da arte com o contemporâneo - este tem sido o interesse recorrente da artista, bem como investigar o significado de uma imagem histórica vista através de uma versão retrabalhada na contemporaneidade. A escolha das polaroides para este reprocesso é questionar as distinções tradicionais entre cultura popular e de culto. O mais importante foi a escolha específica do uso da fotografia polaroide e sua qualidade, ou 
seja, um meio que muda ao longo do tempo e onde a própria imagem pode aparecer eaté desaparecer, como em The Passing of Time (Woman asleep at the Table) (Figura 07), 1995-2008. Ao analisarmos este trabalho inicial, podemos notar que ele contém muitas das questões às quais Christensen retorna e continua a investigar.

O trabalho da artista norueguesa está ligado ao diálogo com obras do passado, nas mais diversas formas e materialidades. Jeannette Christensen explora as capacidades da matéria, não para superar, mas para manter o seu status, as dimensões e os estados de seus fragmentos móveis, incertos, abertos à mudança. Assim, os limites e superfícies de cada objeto que Christensen faz são macios, transitórios, e de múltiplas materialidades.

Christensen persegue constantemente as possibilidades e condições de uma arte engajada socialmente nos termos em que a sua concepção esteja intimamente ligada à matéria, ao corpo, ao mundo social e a sua fragmentação. Ela aborda questões de idade e geração, de gênero, de transitoriedade da vida, de temporalidade - tanto como a passagem implacável do tempo, quanto como sua duração -, caminhando na linha tênue entre representação e ação. Segundo Mieke Bal em Fragments of Matter: "Ela não retrata, a menos que seja uma representação da ação. Ela não representa, a menos que seja uma representação de outros atos de sociabilidade" (BAL, 2009, p. 4, tradução minha). É a tensão entre o tempo - passado e presente -, e a materialidade - suporte de mediação da obra - que sustenta a arte de Jeanette Christensen como arte da matéria, que é também uma arte do tempo.

Se levarmos em consideração o título da exposição The Passing of Time, é exatamente o que vamos encontrar ao analisarmos esta série: a passagem do tempo. O tempo histórico: século XVII para o século XX e o tempo da imagem, sua composição e materialidade. Na Figura 07, vemos uma jovem adormecida. Toda a alegoria da imagem de Vermeer foi suprimida: a porta, a visão para uma outra divisão, o tapete que serve de cobertura para a mesa, a cadeira com as emblemáticas cabeças de leão, as frutas, o jarro, a indicação de um quadro pendurado na parede e a alusão a uma ponta de um mapa. Tudo foi retirado. Apenas os fragmentos da matéria sobreviveram: a moça com a indumentária do século XX: uma camiseta branca, cabelos compridos e uma simples toalha branca que deduzimos estar sobre uma mesa. Se analisarmos a obra do mestre holandês segundo os parâ- 
metros do simbolismo, utilizando as chaves interpretativas segundo a tradição do século XVII e do livro de emblemas de Gabriel Rollenhagen, Livro de Emblemas (1611), o copo de vinho e o jarro fazem alusão ao tema da ingestão do álcool, condenado pelo ethos rígido da época, em que a mulher, como senhora do lar, deveria ser devota e virtuosa. Outros elementos que indicam uma natureza erótica: a taça de fruta e o ovo envolto em tecido, sinal de que algo deve ser evitado. Christensen retira todos esses elementos, fazendo apenas alusão a uma jovem cansada. Cansada da rotina do dia a dia. Do estresse da vida agitada da contemporaneidade.

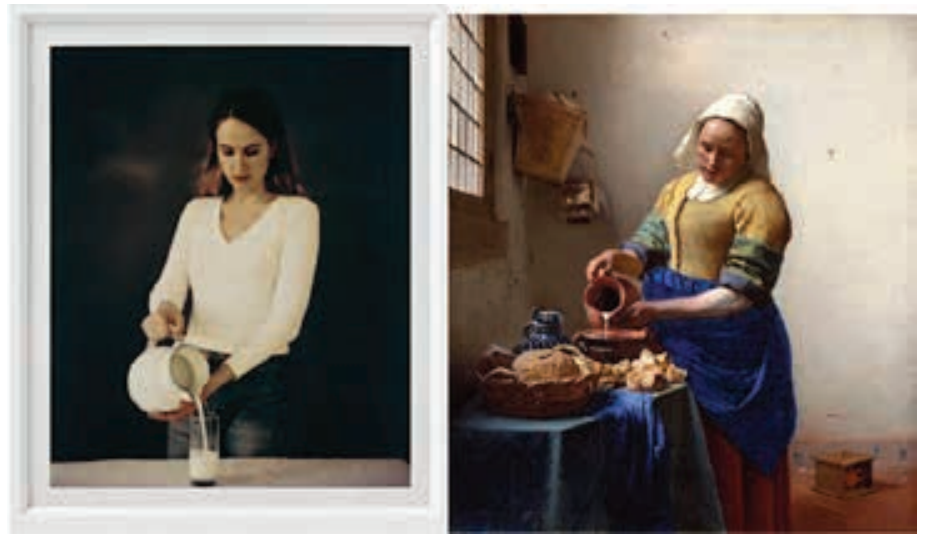

Outro ponto que podemos analisar nesta série é o fundo negro, sem adereços. Não vislumbramos uma janela, apenas um pequeno reflexo no canto esquerdo da polaroide que pode indicar a incidência de luz. Na Figura 8, vemos uma jovem vertendo leite em um copo - enquanto na pintura a leiteira derrama o leite em uma tigela de barro -; mais uma vez todos os elementos alegóricos ou simbólicos são suprimidos. A polaroide retrata uma jovem vestindo jeans e camiseta branca, em oposição à vestimenta do século XVII.

No entanto um detalhe permanece: a pureza da ação. De uma maneira geral as criadas eram retratadas na Holanda como sendo preguiçosas, como, por exemplo, na pintura de Nicolas Maes (1634-1693), A Criada Preguiçosa (Figura 09), mas Vermeer enaltece a sua posição: retrata-a com os olhos baixos, sinal de humildade e num ambiente simples, condizente com a vida de uma criada. $\mathrm{O}$ mesmo podemos ver na polaroide da artista norueguesa: simplicidade, concentração em sua ação.
Figura o8: The Passing of Time (Woman pouring Milk), 1994, Jeannette Christensen e A Leiteira (1658-60), Johannes Vermeer.

Fonte: Disponível em: <http:// www.jeannettechristensen.no/ the-passing-of-time-1994/>e em <http://www.essentialvermeer.com/catalogue/milkmaid. html\#. WrVePZFzIU>. Acesso em: 20 ago. 2018. 
Figura o9: A Criada Preguiçosa, 1655 The Idle Servant, de Nicolas Maes.

Fonte: Óleo sobre painel: 70 $x 53 \mathrm{~cm}$. National Gallery de Londres.

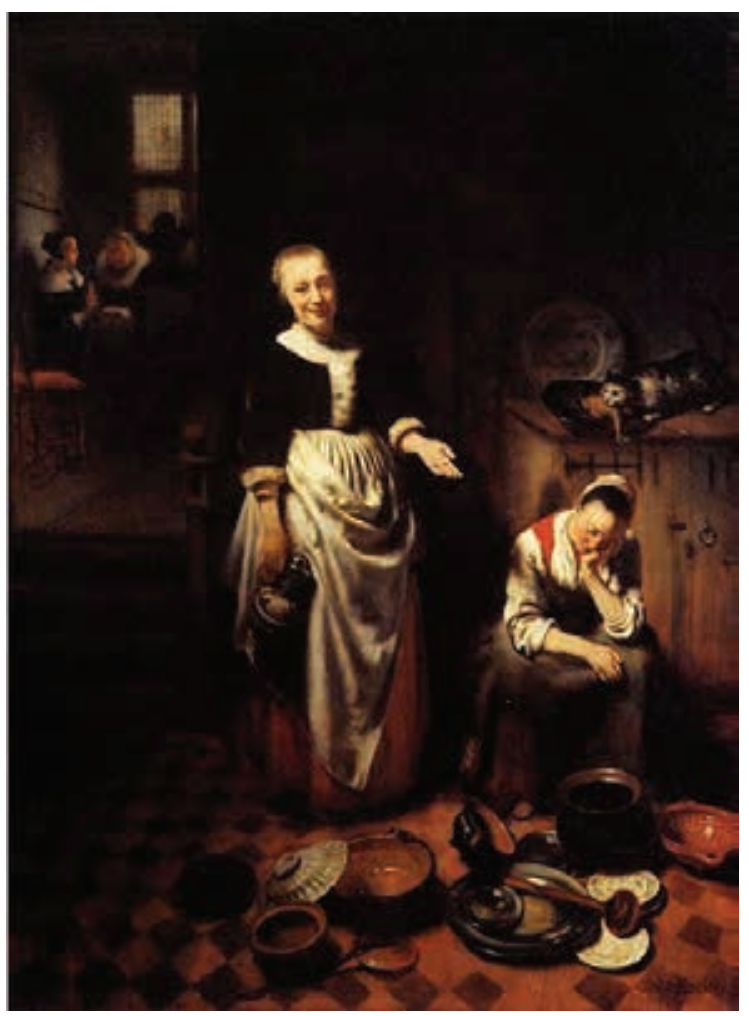

É importante assinalar a importância das criadas que faziam as tarefas externas e das que faziam as tarefas internas - no caso da leiteira, essa era uma função cumprida dentro de casa. Era seu dever cuidar da complexa atividade de produzir a coalhada, a manteiga e o queijo, e da limpeza de todos os utensílios de forma a mantê-los longe de sujidade e germes ou bactérias. A importância dada aos produtos lácteos no século XVII era tão grande que o leite assumia quase uma importância religiosa (SCHNEIDER, 2004).

Uma outra percepção que temos das obras de Christensen diz respeito a suas dimensões. As fotografias em polaroide são divididas em duas telas: a moldura em branco (dimensões: $11 \mathrm{x} 9 \mathrm{~cm}$ ) e apenas o enquadramento (dimensões: $8 \mathrm{x}$ $7,5 \mathrm{~cm}$ ). Os quadros de Vermeer também eram de pequenas dimensões. A Rendeira (1669-70), do Louvre, mede apenas 24,5 x $21 \mathrm{~cm}$. Ao observarmos o espaço expositivo da Figura o4, onde vemos as polaroides emolduradas, observamos que elas chegam relativamente às dimensões de um quadro de Vermeer. Outro ponto comum do uso desta materialidade 
- a fotografia em polaroide em oposição a tinta à óleo, ou a própria fotografia tradicional - é o desvanecer da imagem, que pode vir a desaparecer, quando não devidamente acondicionada, ou nem sequer a aparecer quando o botão é acionado devido à falta de luz. Luz que se faz tão presente na obra do mestre de Delft.

Na solidão da contemporaneidade, uma jovem escreve uma carta à mão (Figura 10), prescindindo de todos os acessórios tecnológicos - seja uma máquina de escrever ou computador, ainda estamos longe da tecnologia dos smartphones -, todos os outros elementos foram retirados da cena. A luz incide no fundo. De olhos baixos, a jovem está concentrada na escrita. A criada, no mundo moderno já não é mais imprescindível: ela já pode escrever sozinha sem a supervisão de alguém, está livre para: ir e vir; escrever, e entregar sua missiva.
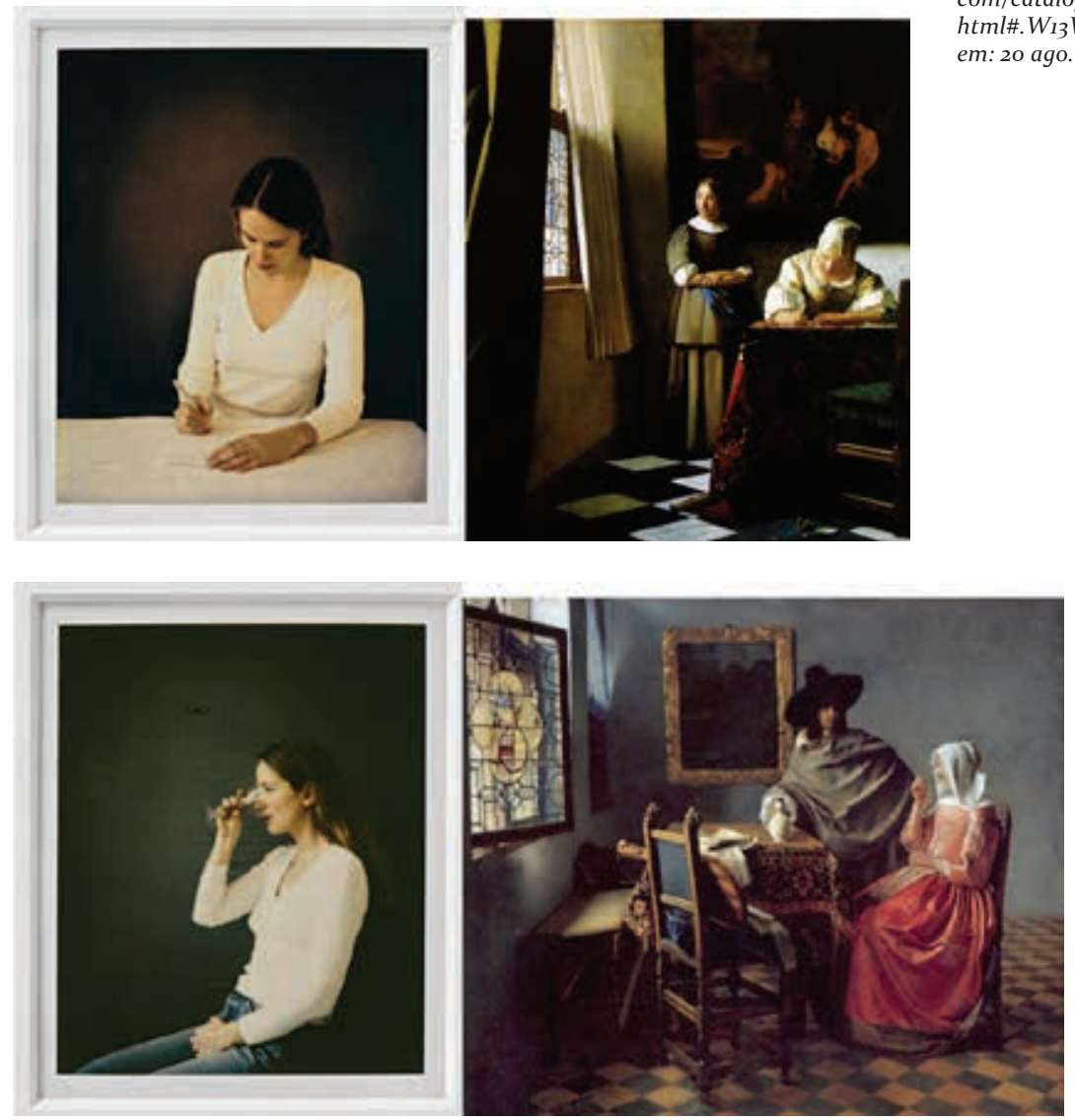

Figura 10: The Passing of Time (Woman writing a Letter), 1994, Jeannette Christensen e Senhora e Criada - Mistress and Maid / (1667), Johannes Vermeer.

Fonte: Disponível em: <http:// www.jeannettechristensen.no/ the-passing-of-time-1994/>e em: <http://www.essentialvermeer.com/catalogue/love_letter. html\#.W13Vx_ZFzIU>. Acesso em: 20 ago. 2018.

Figura 11: The Passing of Time (Woman Drinking), 1994, Jeannette Christensen e

Homem, mulher e vinho (166o61), Johannes Vermeer.

Fonte: Disponível em: <http:// www.jeannettechristensen.no/ the-passing-of-time-1994/> e em: $<$ <ttp://www.essentialvermeer. com/catalogue/glass_of_wine. html\#. W13WBfZFzIU>. Acesso em: 20 ago. 2018. 
Figura 12: The Passing of Time (Woman interrupted), 1994, Jeannette Christensen e A Lição de Música Interrompida (1660-61, Johannes Vermeer. Fonte: Disponivel em: <http:// www.jeannettechristensen.no/ the-passing-of-time-1994/>e em: <http://www.essentialvermeer.com/catalogue/girl_interrupted_in_her_music.html\#. $W_{13} W V v Z F z I U>$. Acesso em: 20 ago. 2018.
A Figura 11 é sutil em seus detalhes. Mais uma vez, Christensen retira todos os objetos alegóricos e simbólicos da cena. Suprime também o homem que está na pintura de Vermeer, no entanto, nos deixa um detalhe: o desenho na parede do fundo, uma insinuação de um bigode. A presença do cavalheiro está inserida de forma oculta. Será uma ameaça? Afinal a personagem feminina está consumindo vinho, que seria um elemento de infidelidade (mais uma vez segundo o Livro de Emblemas de Rollenhagen). Curiosamente esta polaroide terá uma incidência de luz na parede do fundo maior que as outras da mesma série.

Na Figura 12, esta jovem interrompe que atividade? Retratada sentada em uma cadeira, olha fixamente para o observador - um olhar que por sua vez revela medo, surpresa -, segura uma folha de papel, a qual tem um fundo escuro e um ponto luz que incide sobre ela; não temos elementos que possam revelar em que ação ela foi interrompida. Os fragmentos da matéria fazem falta. A pintura de Vermeer e toda a simbologia que ela carrega, seja ou não representativa da cena ali retratada, nos dão indicação ou nos sugerem algum tipo de ação por parte do cavalheiro e da jovem.
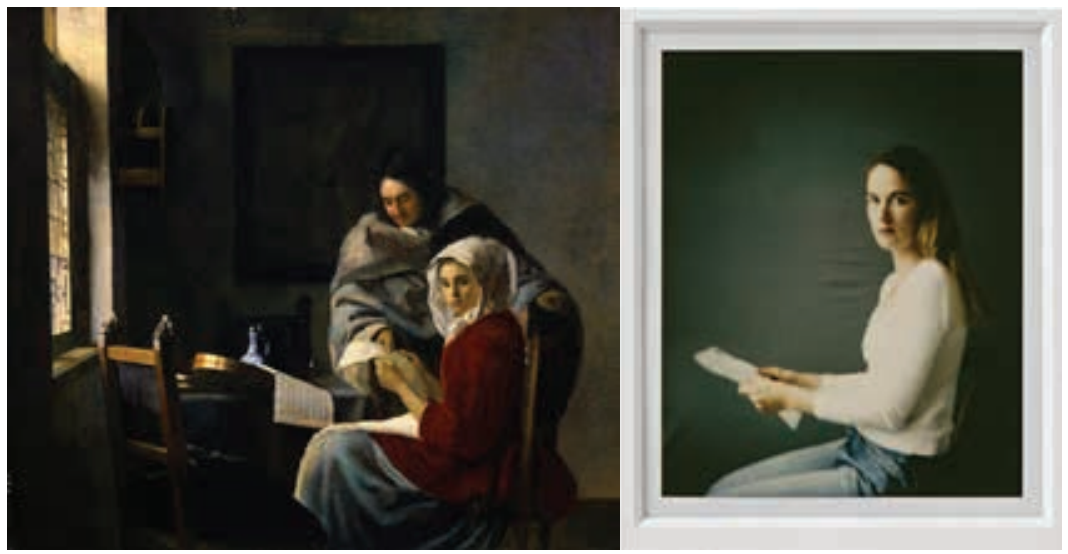

Jeannette Christensen trabalha a temática de Vermeer, segundo dois critérios que podem se justapor: o primeiro suprime todos os elementos simbólicos e alegóricos de suas fotografias em polaroide, deixando as mulheres contemporâneas sós, algo recorrente no mundo atual. Ou, numa segunda análise, ao utilizar a técnica da polaroide, que desvanece a imagem, pode sugerir que os próprios elementos incluídos na 
pintura do mestre holandês tenham desaparecido pelo passar do tempo e da exposição das polaroides à luz intensa. Para esta análise podemos invocar Georges Didi-Huberman, em Diante do Tempo, que sintetiza com precisão o trabalho de Christensen:

É obsessão? É algo ou alguém que volta sempre, sobrevive a tudo, reaparece de tempos em tempos, enuncia uma verdade quanto à origem. É algo ou alguém que não conseguimos esquecer. Mas que não podemos reconhecer com clareza. (DIDI-HUBERMAN, 2016, p. 103).

\section{Considerações finais}

Imagens estáticas, imagens em movimentos, narrativas que se encontram sempre na tentativa de um resgate da memória. Todas as imagens estão impregnadas de uma potência, quando escolhidas têm um referente nosso, apesar de já fazerem parte do mundo da cultura, de estarem circulando, ao serem escolhidas, apropriadas pos nós, fazem o resgate de um imaginário que é nosso.

$\mathrm{O}$ aliciante em pesquisar imagens, suas associações e correlações, é ter a compreensão de que o estudo não se finda, surgindo novos olhares, dando ensejo a uma nova jornada. Novos horizontes são vislumbrados através de uma cortina entreaberta, uma janela. Johannes Vermeer era mestre em nos deixar fora da cena ao mesmo tempo em que nos convidava para entrar em seus domínios, sutilmente. As nachleben de Aby Warburg nos levam para além destas janelas e cortinas, entrevendo um mundo onde a contemporaneidade é a protagonista, onde o passado sobrevive no instante presente, nos direcionando para o futuro, numa busca incessante entre formas simbólicas que se relacionam entre si. Em busca da sua sobrevivência

NOTAS

1 Títulos originais: The Music Lesson, de Katherine Weber, The Girl with a Pearl Earring, de Tracy Chevalier, Girl in Hyacinth Blue, de Susan Vreeland, The Forger, de Paul Watkins, The Dance of Geometry, de Brian Howell, Girl, Interrupted, de Sussana Kaynes e, Vermeer's Daughter, de Barbara Shoup. 


\section{Referências}

ALPERS, Svetlana. A arte de descrever: a arte holandesa no século XVII. Tradução Antonio de Pádua Danesi. São Paulo: Edusp, 1998.

AGAMBEN, Giorgio. Aby Warburg e a ciência sem nome. ArteEEnsaios, Rio de Janeiro, n. 19, p. 132-143, jan. 2010. [Dossiê Warburg].

BAL, Mieke. Fragments of matter - Jeannette Christensen. Bergen: Kunsthogskolen i Bergen, 2009.

University of Chicago Press, 1999.

Quoting Caravaggio. Chicago; Londres: The

BAXANDALL, Michael. Padrões de intenções. A explicação histórica dos quadros. Tradução Vera Maria Pereira. São Paulo: Companhia das Letras, 2006.

BLADE Runner, o caçador de andróides. Direção: Ridley Scott. Los Angeles: Warner Bross, 1982. 1 DVD (117 min), widescreen, color.

BURKE, Peter. Testemunha ocular. O uso de imagens como evidência histórica. Tradução Vera Maria Xavier dos Santos. São Paulo: Editora Unesp, 2017.

CHEVALIER, Tracy. Moça com brinco de Pérola. Lisboa: Temas e Debates, 2004.

DIDI-HUBERMAN, Georges. Diante do tempo. História da Arte e anacronismo das imagens. Tradução de Vera Cruz Nova e Márcia Arbex. Belo Horizonte: Editora UFMG, 2016.

. A imagem sobrevivente. História da arte e tempos dos fantasmas segundo Aby Warburg. Tradução Vera Ribeiro. Rio de Janeiro: Contraponto, 2013.

HERNÁNDEZ, Fernando. De qué hablamos cuando hablamos de Cultura Visual? Revista Educação e Realidade, v. 30, n. 2, jul./dez. 2005. Disponível em: <http://seer.ufrgs.br/ educacaoerealidade/article/view/12413>. Acesso em: 29 dez. 2017.

HOWELL, Brian. The dance of geometry. Nova Iorque: Toby Press Ltd, 2002.

MONTIAS, John Michael. Vermeer and his millieu: A web social history. Princeton: Princeton University Press, 1998.

SALGUEIRO, Heliana Angotti. Introdução. In: BAXANDALL, Michael. Padrões de Intenções. A explicação histórica dos quadros. Tradução Vera Maria Pereira. São Paulo: Companhia das Letras, 2005.

SCHNEIDER, Robert. Vermeer. Lisboa: Taschen-Público, 2004. 
SHOUP, Barbara. Vermeer's Daughter. Zionsville: Guild Press Emmis Publishing, LP, 2003.

SWILLENS, P. T. A. Johannes Vermeer, painter of Delft 1632-1675. Utrecht: Spectrum, 1950.

VREELAND, Susan. Girl in Hyacinth Blue. Denver: MacMurray \& Beck, 2002.

WEBER, Katharine. A Lição de Música. Lisboa: Temas e Debates, 2000.

WHEELOCK JUNIOR, Arthur K. Johannes Vermeer. Washington; Haia; New Haven; Londres: National Gallery of Art; Royal Cabinet of Paintings Mauritshuis; Yale University Press, 1995 [catálogo]. 


\section{CRISTINA SUSIGAN \\ csusigan@gmail.com}

Doutora em Educação, Arte e História da Cultura pela Universidade Presbiteriana Mackenzie. Foi Bolsista Capes. Mestre em Estudos Americanos pela Universidade Aberta de Portugal. Exerceu a docência no ensino superior no Instituto Politécnico do Porto, Portugal, na área dos estudos visuais. Em suas pesquisas, dedica-se à apropriação nas artes, história, teoria e crítica de arte e relação inter-artes. Tem ministrado cursos livres na área de artes visuais e linguagem audiovisual. Pesquisadora independente sem vínculo. 